\title{
Experimental Study on the Effects of Fault Movement on the Engineered Barrier System"
}

\author{
Morimasa NAITO $^{* *}$, Yuya SAITO ${ }^{* *}$, Kenji TANAI $^{* *}$ and Mikazu YUI ${ }^{* *}$ \\ **Japan Atomic Energy Agency \\ 4-43 Muramatsu, Tokai, Ibaraki 319-1194 Japan \\ E-mail: naito.morimasa@jaea.go.jp
}

\begin{abstract}
An experimental approach is introduced for understanding how the engineered barriers of a deep geological repository system are affected by fault movement. The experiments are conducted using laboratory simulation test equipment. So far, the experiments indicate that the metal overpack is rotated within the bentonite buffer due to its plasticity, but not breached. Numerical modeling is also developed to supplement the range of the experiments, which is limited by the capability of the test equipment.
\end{abstract}

Key words: Fault Movement, Shear Test Experiment, Shear Rate, Fault Displacement, Geological Disposal, HLW Repository, EBS

\section{Introduction}

The concept of geological disposal for high-level radioactive waste (HLW) in Japan is similar to that in other countries, being based on a multibarrier system which combines the natural geological environment with engineered barriers ${ }^{(1)}$. The safety concept assumes that disruptive events can be excluded by site selection. Geological environments having favorable characteristics for the disposal system provide the basis for repository design. If the safety functions of the geological disposal system can be assured, minor amounts of radioactivity released from the HLW repository will further decay and concentrations will be reduced by dilution during the long migration period in the geosphere. Thus, the basic functions of the geological disposal system provide intrinsic long-term, passive safety.

In June 2000, the "Specified Radioactive Waste Final Disposal Act" was enacted in Japan to provide an organizational framework for the siting and construction of a geological repository for HLW. A new organization, the Nuclear Waste Management Organization of Japan (NUMO) was established to implement the plan, which explicitly requires stepwise implementation. NUMO will proceed with siting initiated by an open solicitation procedure (a call for volunteer host municipalities) ${ }^{(2)}$ although no volunteer has yet come forward at the present stage. Site selection will start from such volunteers and narrow in on a preferred option based on increasingly detailed characterization work. Particular consideration is given to the long-term stability of the geological environment, taking into account the fact that Japan is located in a tectonically active zone ${ }^{(3)}$.

Fault movement is one natural event which may bring about a significant change in the performance of the geological disposal system for HLW and is therefore subject to thorough investigation during the phase of site selection, with the aim of avoiding any significant influence by such phenomena. It is presumed that fault movement could influence a deep disposal system principally by the formation of new pathways for groundwater flow, 
particularly if these were to intersect the repository system, in particular the engineered barrier system (EBS).

From the point of view of the initial repository siting process, the most important faults are those that have shown significant and repeated movement within the time frame of the current tectonic regime and that may show such movements in the future (assuming that the present tectonic regime persists). These faults are referred to hereafter as "active faults". The distribution and location of major active faults in Japan are well documented and it is therefore possible to avoid significant influences of these features during the repository siting process ${ }^{(1)}$. Fault characteristics, such as magnitude of past activity and influence on regional hydrogeology, will be determined by site investigation activities. This information will be used to confirm the feasibility of siting a repository outside the zone of significant influence of future fault movement, where the EBS and the geosphere can be assured to perform their planned functions.

However, minor faults located far from major fault zones, which are generally categorized as small-scale in terms of displacement rate, are difficult to identify and characterize, even in the detailed investigation stage. Figure 1 is a plot of the percentage of active faults showing detectable movement at the surface as a function of associated earthquake intensity ${ }^{(4)}$. As shown in Fig. 1, fault movements due to earthquakes with magnitudes less than 6.5 were extremely hard to identify.

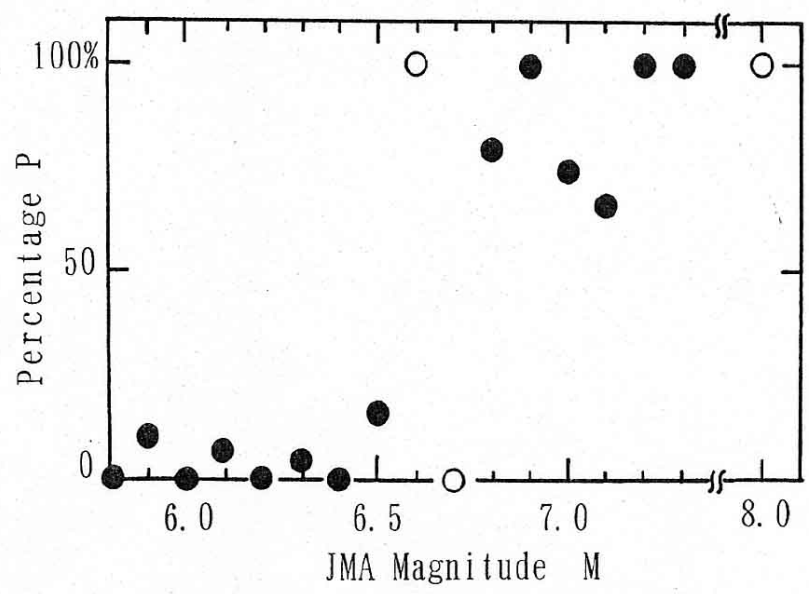

Fig.1 Faults showing detectable movement at the surface as a function of earthquake magnitude (open circle indicates a single event) ${ }^{(4)}$

From the viewpoint of repository design as well as site selection, it is important to evaluate the effect of such fault movements on the performance of the disposal system, in particular that of the EBS. We have therefore conducted experiments aimed at understanding the impact of fault movement on the EBS which directly affects the disposal system. This paper summarizes the current status and technical findings of a series of experiments with a supporting numerical approach.

\section{Approach of the Study}

Figure 2 shows the relationship between shear rate and magnitude ${ }^{(5)}$. It is found that the shear rate due to earthquakes with magnitudes greater than 5.5 averages around $0.8 \mathrm{~m} / \mathrm{s}$. According to Matsuda ${ }^{(6)}$, the relationship between displacement and magnitude can be represented by Eq. (1). For an earthquake of magnitude 6.5 , for example, the equation predicts that the displacement $\mathrm{D}$ will be $790 \mathrm{~mm}$. 
$\log \mathrm{D}=0.6 \mathrm{M}-2.0$

In Eq. (1) D is displacement of the fault, $\mathrm{M}$ is magnitude of earthquake.

Taking this into account, the present study focuses on fault movement with displacement in the order of $1 \mathrm{~m}$ and shear rates of about $1 \mathrm{~m} / \mathrm{s}$. We have adopted an experimental approach to improving the understanding of how the EBS is affected by fault movement in the case where the fault directly impacts the repository. The experiments are conducted using laboratory simulation test equipment on a scale of 1:20 ${ }^{(7)(8)}$, which is described in detail in the next chapter. Due to the limit of mechanical capacity of the test equipment, the tests have to be conducted an order of magnitude below the reference values noted above. It is therefore necessary to develop a numerical model in order to extrapolate results to the critical range. The reliability of the numerical model is tested by comparison with experimental results over the full range available.

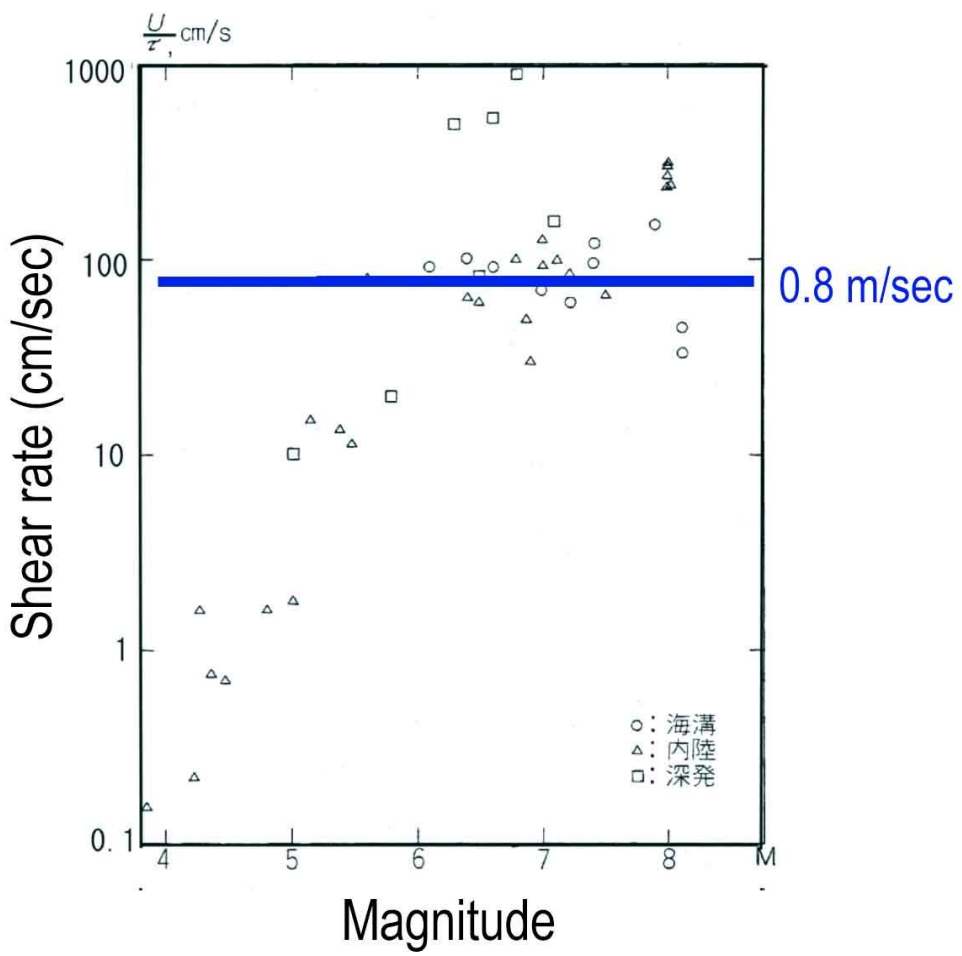

Fig.2 Shear rate of fault movement against earthquake magnitude ${ }^{(5)}$

\section{Laboratory Shear Test Experiment}

\subsection{Experimental Apparatus}

To examine the effects of fault movement on the EBS, laboratory shear tests are conducted using a 1:20 scale model named the BORE-SHEAR ${ }^{(7)(8)}$, shown in Fig. 3. The BORE-SHEAR can simulate shear displacement up to $200 \%$ of the buffer thickness (i.e. $100 \mathrm{~mm}$ ) and a shear rate up to $0.1 \mathrm{~m} / \mathrm{s}$ respectively. The equipment consists of:

- A cylindrical test container, in which the hollow steel cylinder representing the overpack with the surrounding bentonite buffer material is installed. This can be sheared at the center, in a direction perpendicular to the axis

- The loading system

- The water supply system for buffer saturation 
- The data acquisition system.

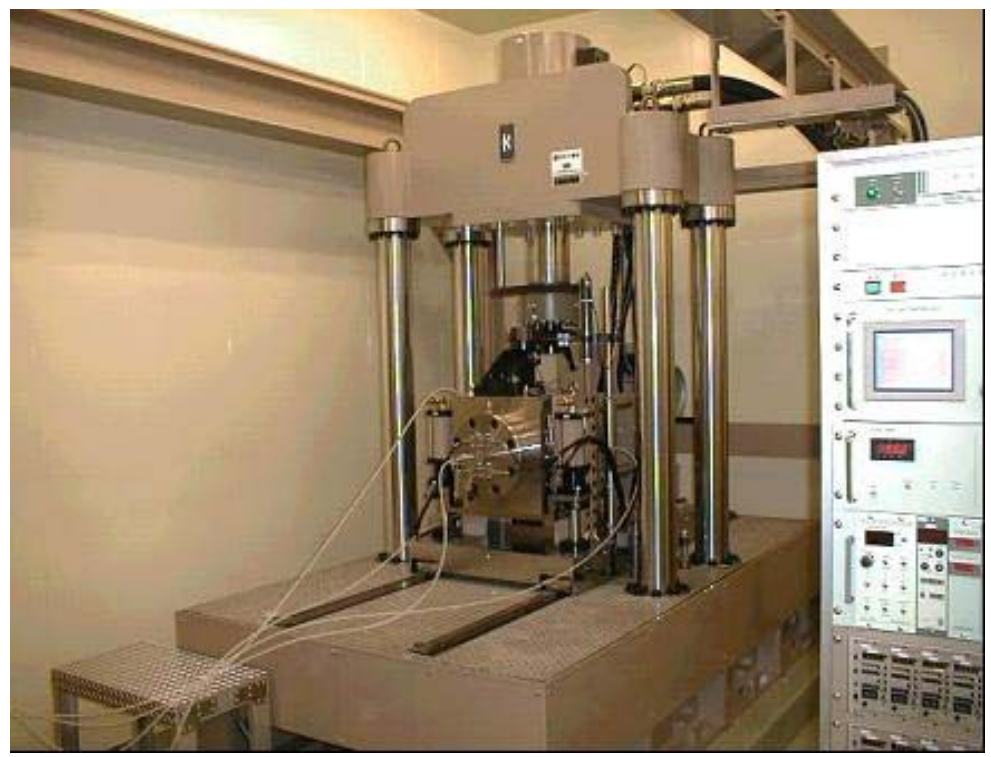

Fig.3 Laboratory simulation test equipment on a scale of 1:20 (BORE-SHEAR)

The EBS is simulated with a hollow steel cylinder, representing the overpack, surrounded by bentonite/sand buffer material. Before the shear tests, the bentonite buffer is saturated with distilled water until the swelling pressure reaches a steady state. Then, the test model is sheared at the center, in a direction perpendicular to the cylindrical axis (see Fig. 4).

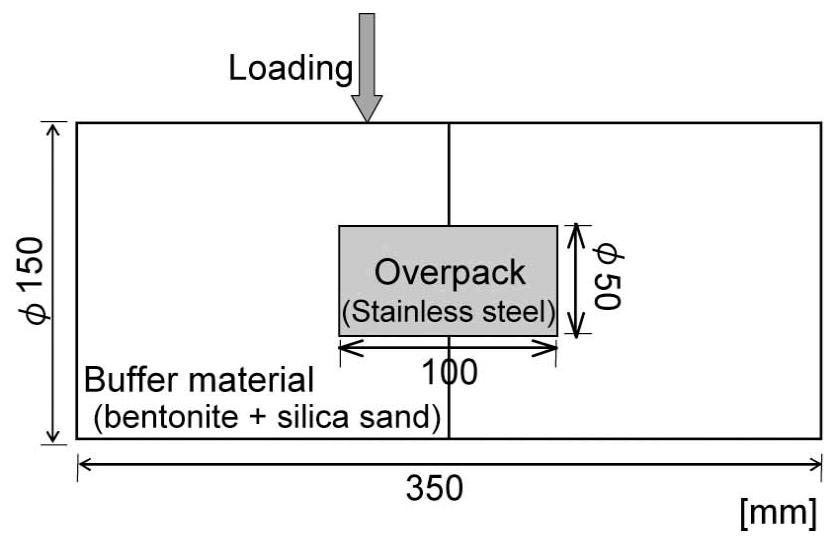

Fig.4 Concept of the shear test

All tests are carried out at room temperature, $20 \pm 1^{\circ} \mathrm{C}$. Stress in the buffer material and the deformation of the cylinder caused by the shearing are measured. The total pressure and porewater pressure in the buffer material, the force required to shear the buffer and the displacement are monitored throughout the experiment.

Figure 5 shows the specifications of the cylindrical test container and locations of the transducers installed for monitoring. The container is designed to supply water at a constant pressure to the buffer during the saturation phase. The force transducer measures the loading force required to shear the test container and the strain transducer measures the displacement of the test container during shearing. The total pressure and porewater pressure transducers are located on the inner side of the container and are installed considering the symmetry of the tests; the total pressure transducers are installed in one half 
of the container while the porewater pressure transducers are installed in the other half. Figure 5 also shows the specifications of the simulated overpack and the location of the total pressure transducers. The buffer material is a mixture of $70 \mathrm{wt} \%$ bentonite and $30 \mathrm{wt} \%$ silica sand with an initial water content in the bentonite of around $7 \%$. The mixture is pre-compacted to cylindrical blocks surrounding the overpack. The dry density of the buffer is $1.6 \times 10^{3} \mathrm{~kg} / \mathrm{m}^{3}$.
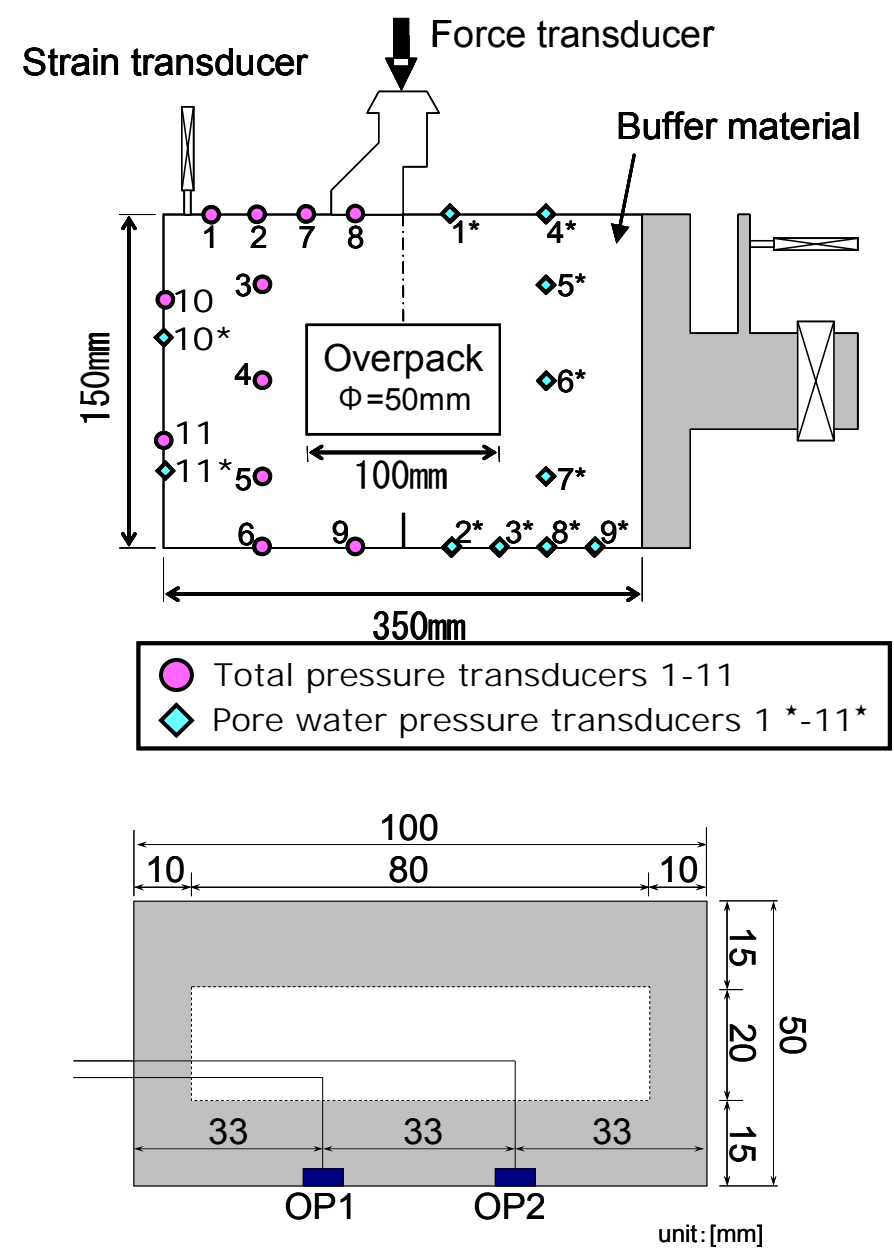

Fig.5 Measuring points: test container (top), simulated overpack (bottom)

\subsection{Experimental Conditions}

Four test cases are carried out under two different sets of shearing conditions (Table 1).

Table 1 Shear test cases and experimental conditions

\begin{tabular}{|c|c|c|}
\hline Test case & Shear rate & $\begin{array}{c}\text { Shear displacement } \\
\text { (ratio to thickness of buffer) }\end{array}$ \\
\cline { 1 - 1 } Case-1 & \multirow{2}{*}{$0.1 \mathrm{~m} / \mathrm{s}$} & $40 \mathrm{~mm}(80 \%)$ \\
\cline { 1 - 1 } Case-2 & \multirow{2}{*}{$0.01 \mathrm{~m} / \mathrm{s}$} & $70 \mathrm{~mm}(140 \%)$ \\
\cline { 1 - 1 } Case-3 & \\
\cline { 1 - 2 } Case-4 & & \\
\hline
\end{tabular}

In the tests, the bentonite is saturated by injection of distilled water at a constant pressure of 0.2 $\mathrm{MPa}$, taking more than six months to become saturated. A very limited number of experiments is therefore conducted in a year. After the bentonite is saturated, the 
buffer material is sheared by moving one half side of the container, while the other half side remains fixed within the loading machine. A shear displacement of $40 \mathrm{~mm}$ is equivalent to $80 \%$ of the thickness of the buffer material. The shearing is conducted under undrained conditions. In both tests, the force required for shearing, the shear displacement and the total pressure and porewater pressure acting on the container are measured, in addition to the total pressure acting on the model overpack.

\subsection{Results of the Experiments}

For all cases, there is no visible damage to, or deformation of, the overpack, although it rotates within the buffer as illustrated in Fig. 6. The figure represents the final orientation of the overpack at the end of the experiment.

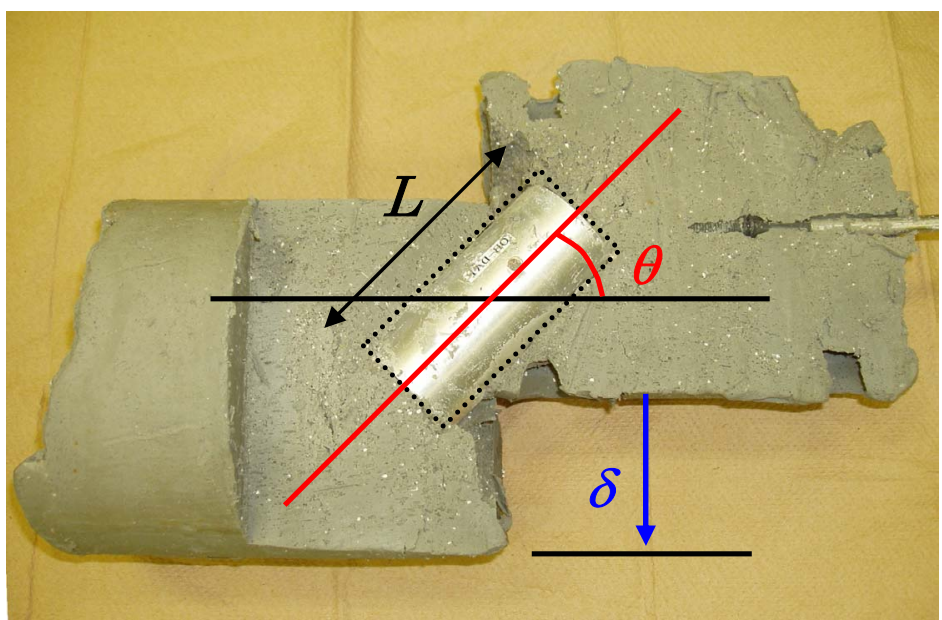

Fig.6 Sheared EBS after the test

Assuming no significant resistance of the buffer or overpack contact with the equipment wall, the rotation angle $\theta$ is theoretically defined by:

$$
\theta=\sin ^{-1}(\delta / \mathrm{L})
$$

In Eq. (2) $\delta$ is shear displacement and $L$ is the length of the overpack. As shown in Table 2, the measured values for the overpack rotation angle are almost the same as the theoretical ones in all cases. This indicates that the overpack is rotated without any significant resistance from the buffer due to its plastic behavior.

Table 2 Rotation angle of overpack

\begin{tabular}{|c|c|c|}
\hline Test case & Theoretical & Measured \\
\hline Case-1 & \multirow{2}{*}{$24 \pm 3^{\circ}$} & $25^{\circ}$ \\
\cline { 1 - 1 } \cline { 3 - 3 } Case-2 & & $27^{\circ}$ \\
\hline Case-3 & \multirow{2}{*}{$44 \pm 3^{\circ}$} & $45^{\circ}$ \\
\hline Case-4 & & $44^{\circ}$ \\
\hline
\end{tabular}

Almost all the experimental data consists of total pressure due to a malfunction of the porewater pressure transducers. Figure 7 shows the total pressures on the overpack as a function of shear displacement during the test period. The total pressure measured at point OP2 varies with the amount of shear and reaches a maximum, which depends on the shear rate. In contrast, for Case 2, the pressure at point OP1, which is the opposite side of OP2 in terms of the displacement, initially decreases to around $-0.1 \mathrm{MPa}$ at the time of shearing, but then increases in parallel to OP2. It would appear that, at this location, the test container 
is forced to move down, but overpack rotation is slightly delayed after shearing due to the plasticity of the bentonite buffer. Canister lifting allows the bentonite buffer below the overpack to expand and therefore the pressure measured decreases.

In the Japanese disposal concept, the overpack is designed to withstand external pressures such as a groundwater hydrostatic pressure (max. 9.8 $\mathrm{MPa}$ ) and buffer consolidation stress due to creep deformation and corrosion product expansion (0.86 $\mathrm{MPa})$ for a geological environment of hard crystalline rock ${ }^{(1)}$. The thickness of the carbon steel overpack to ensure pressure resistance is $150 \mathrm{~mm}$. This design specification has a high safety margin, even in the case of extra shear stress (e.g. 2.6 MPa from Fig. 7) arising from fault movement acting on the overpack in addition to the above total pressures (10.7 MPa). Since the fault movement for the experiment is, however, one order of magnitude lower than the reference range of this study, this margin is subject to further discussion utilizing a numerical modeling approach.

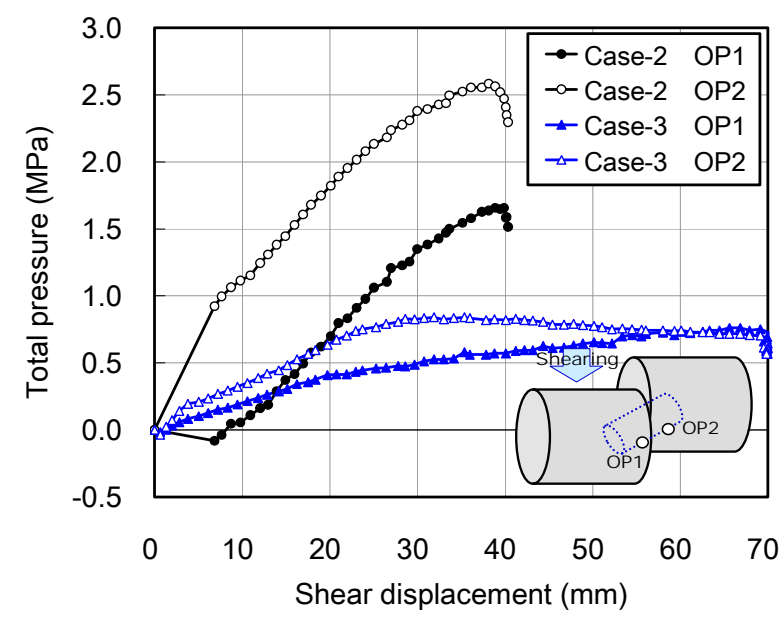

Fig.7 Total pressures measured on the overpack as a function of shear displacement

\section{Numerical Analysis of the Model Tests}

Due to the limitation of the experimental approach in terms of capabilities of the test equipment (one order of magnitude lower movement than the target range), a numerical modeling approach is used to simulate the full range of displacement $(1 \mathrm{~m})$ and shear rate $(1$ $\mathrm{m} / \mathrm{s}$ ). The reliability of the numerical model is tested by comparison with the available range of experimental results. The three-dimensional, non-linear, finite element model utilizes the computer code ABAQUS ${ }^{(9)}$.

\subsection{Finite Element Mesh}

Figure 8 shows the finite element mesh used for the model simulations, which consists of four parts;

- normal buffer: clay material model

- shear zone: same as normal buffer material

- overpack: metal material model

- near-field rock: equipment represented by porous metal model. 


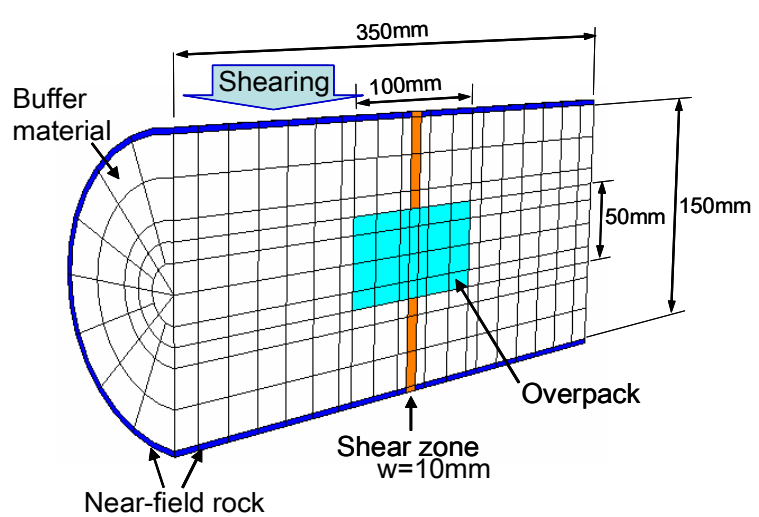

Fig.8 Finite element mesh for numerical analysis

\subsection{Material Models}

Earlier analytical studies were carried out for a Swedish EBS design ${ }^{\text {e.g. }}{ }^{-(10)-(12)}$. In these studies, the influence of shear rate was examined. It was concluded that the total stress model was applicable for fast movement of buffer material for undrained conditions.

The buffer material can be defined as elasto-plastic, based on critical state plasticity theory; a modified Cam-clay model ${ }^{(13)(14)}$. This theory involves a strain rate decomposition, in which the rate of the mechanical deformation is decomposed into an elastic part and a plastic part, an elasticity theory, a yield surface, a flow rule and a hardening rule. The overpack and the near-field rock are modeled as elastic materials, based on the observation that the overpack was not noticeably deformed in the tests.

The near-field rock is modeled with properties allowing water to drain from the buffer to the rock. The shear zone at the center of the test container is modeled using a narrow mesh between the two blocks of "normal" buffer material. Water is allowed to drain along the boundary surface of the shear zone, because this is not constrained by the near-field rock.

\subsection{Analytical Conditions}

The numerical calculation is carried out based on a coupled fluid-solid phase mechanical analysis. The calculation proceeds in two stages: the swelling pressure is derived in the first stage, followed by shear in the second stage. The swelling pressure is assumed to be $0.7 \mathrm{MPa}$, based on the experimental data. The behavior of the bentonite porewater is affected by the total pressure on the buffer. Each calculation is carried out assuming a porous medium for the surrounding near-field rock, with three different hydraulic conductivities $\left(10^{-8}, 10^{-7}, 10^{-6} \mathrm{~m} / \mathrm{s}\right)$ because this is hard to define in the experimental case where it is simulated by a sintered filter. The width of the shear zone is set to $10 \mathrm{~mm}$ for the calculations. Table 3 shows the main parameters used for simulating the experiments.

Table 3 Parameters for the numerical analysis

\begin{tabular}{|c|c|c|c|c|}
\hline \multirow{2}{*}{ Overpack } & Modulus of elasticity & $E$ & $2.07 \mathrm{E}+05$ & $\mathrm{MPa}$ \\
\hline & Poisson's ratio & $\mathrm{V}$ & $3.0 \mathrm{E}-01$ & - \\
\hline \multirow{7}{*}{ Buffer } & Poisson's ratio & $\mathrm{V}$ & $1.0 \mathrm{E}-03$ & - \\
\hline & Compression index & $\lambda$ & 1.17E-01 & - \\
\hline & Swelling index & $\kappa$ & $6.23 \mathrm{E}-02$ & - \\
\hline & Critical state parameter & $\mathrm{M}$ & $6.3 \mathrm{E}-01$ & F \\
\hline & Hydraulic conductivity & $\mathrm{K}$ & $4.5 \mathrm{E}-13$ & $\mathrm{~m} / \mathrm{s}$ \\
\hline & Initial void ratio & $\mathrm{e}_{0}$ & 7.0E-01 & \\
\hline & Initial effective stress & - & $7.0 \mathrm{E}-01$ & $\mathrm{MPa}$ \\
\hline \multirow{3}{*}{$\begin{array}{l}\text { Surrounding } \\
\text { near-field rock }\end{array}$} & Modulus of elasticity & $E$ & $2.07 \mathrm{E}+05$ & $\mathrm{MPa}$ \\
\hline & Poisson's ratio & $\mathrm{V}$ & $3.0 \mathrm{E}-01$ & - \\
\hline & Hydraulic conductivity & $\mathrm{K}$ & $\begin{array}{l}1.0 \mathrm{E}-08 \\
1.0 \mathrm{E}-06 \\
1.0 \mathrm{E}-06\end{array}$ & $\mathrm{~m} / \mathrm{s}$ \\
\hline
\end{tabular}




\subsection{Results of the Calculations}

Figures 9 and 10 show the comparisons of the calculated results with the experiments for Case 2 and Case 3, respectively, in terms of the total pressures on the overpack (at points OP1 and OP2) against the shear displacement. Total pressure is the sum of the effective stress and the porewater pressure, which is controlled by the latter pressure.
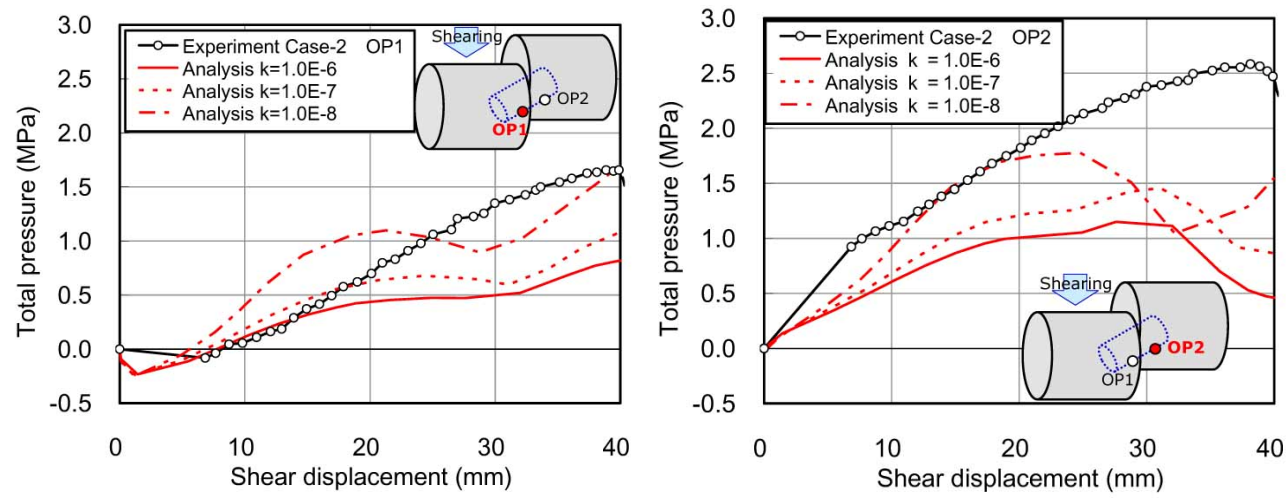

Fig.9 Comparison of numerical analysis and experimental results: total pressure against shear displacement (Case 2)
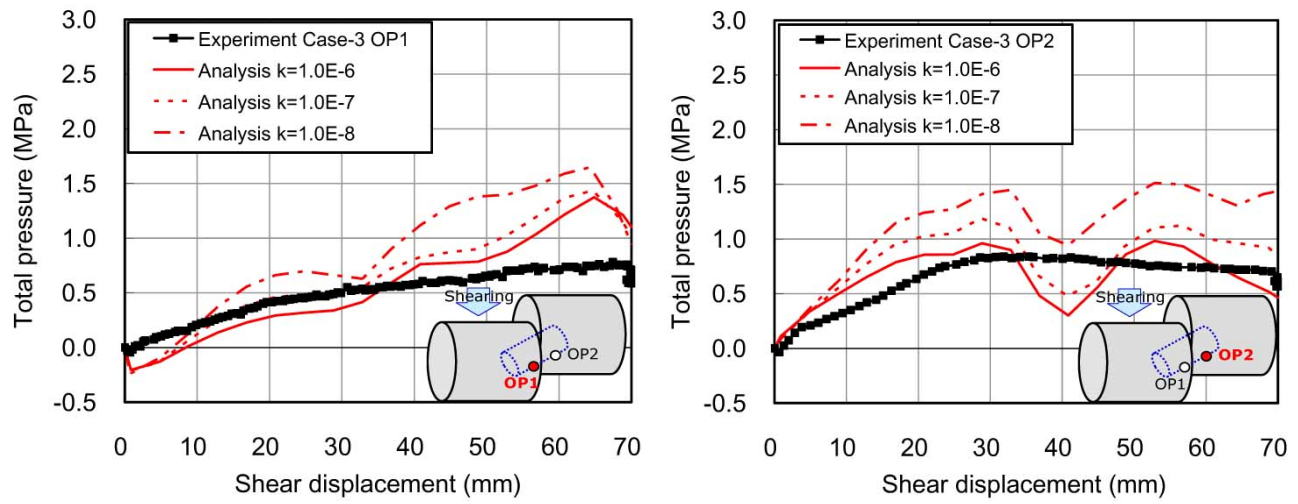

Fig.10 Comparison of numerical analysis and experimental results: total pressure against shear displacement (Case 3)

The calculations with a hydraulic conductivity of the surrounding rock of $10^{-6} \sim 10^{-7} \mathrm{~m} / \mathrm{s}$ appear to be in fair agreement with or showing a similar trend to the experimental results up to $20 \sim 30 \mathrm{~mm}$ displacement, but the differences then become greater. This breaking point corresponds to around half of the buffer thickness. To clarify the data shown in Figs. 9 and 10, the difference of calculated results from the observed data is shown in Fig. 11 for Case 2 and Case 3 (except for the cases of $10^{-8} \mathrm{~m} / \mathrm{s}$ ).

The greater difference arising after 20 30 $\mathrm{mm}$ displacement is considered due to the finite element mesh model reaching the limit of the above breaking point. This is because each mesh is treated as a continuous system and never splits off, even if it is actually broken-off by shearing. The limits can be seen in Fig. 12, which shows the change of porewater pressure contours with displacement. Considerable deformation of the mesh appears not only in the shear zone but also along the surface of the overpack after 20 30 $\mathrm{mm}$ displacement. This suggests that it is necessary to use an alternative model; for example, a model that includes a contact mesh element, which has friction sliding along the elements.

In Fig. 11, the observed pressure at point OP2 for Case 2 appears anomalous with relatively higher than the calculated results up to around $20 \mathrm{~mm}$ displacement. The shear rate for Case $2(0.1 \mathrm{~m} / \mathrm{s})$ is one order of magnitude higher than that for Case $1(0.01 \mathrm{~m} / \mathrm{s})$. It 
is considered that the OP2 pressure is increased due to the decreasing hydraulic conductivity of the surrounding rock at the time when a rapid change in displacement occurs. This interpretation is supported by the actual OP2 pressure being in close agreement with the calculation up to around $20 \mathrm{~mm}$ displacement in the case of lower hydraulic conductivity $\left(10^{-8} \mathrm{~m} / \mathrm{s}\right.$ ) (see Fig. 9). However, there appears to be no such change in the OP1 pressure. This is because the effect of rapid pressure buildup can be released from the shear zone. Consequently the former (OP2) is a more affected side than the latter (OP1) when the fault movement directly affects the EBS.
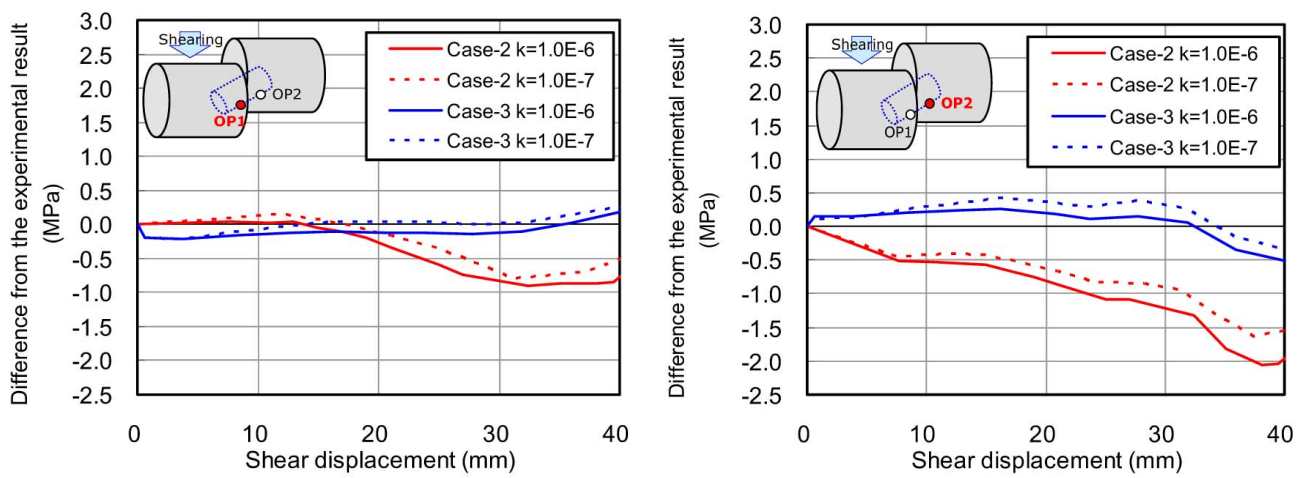

Fig.11 Difference of calculated results from the observed data: total pressure against shear displacement (left: OP1, right: OP2)

\section{Concluding Remarks}

The total pressure on the EBS increases as a function of shear rate. In these experiments, however, no damage or deformation of the overpack is observed. The overpack is readily rotated in response to shearing, due to the plastic behavior of the bentonite buffer. It is also observed that the pressure on the compression side (i.e. OP2) increases during shearing, while the pressure on the tensile side (i.e. OP1) initially decreases and then increases again. The maximum total pressure depends on the shear rate.

Numerical analysis can simulate the increase in the total pressure during shearing and the influence of shear rate. Through comparison with experimental results, it is found that the current numerical model can estimate the impact on the EBS caused by the fault movement displacement up to half of buffer thickness.

These tests have been conducted under conditions an order of magnitude lower than the reference maximum value due to the limitations in the mechanical capacity of the test equipment. It is therefore crucial to further develop supporting numerical models to allow extrapolation into the critical range. 

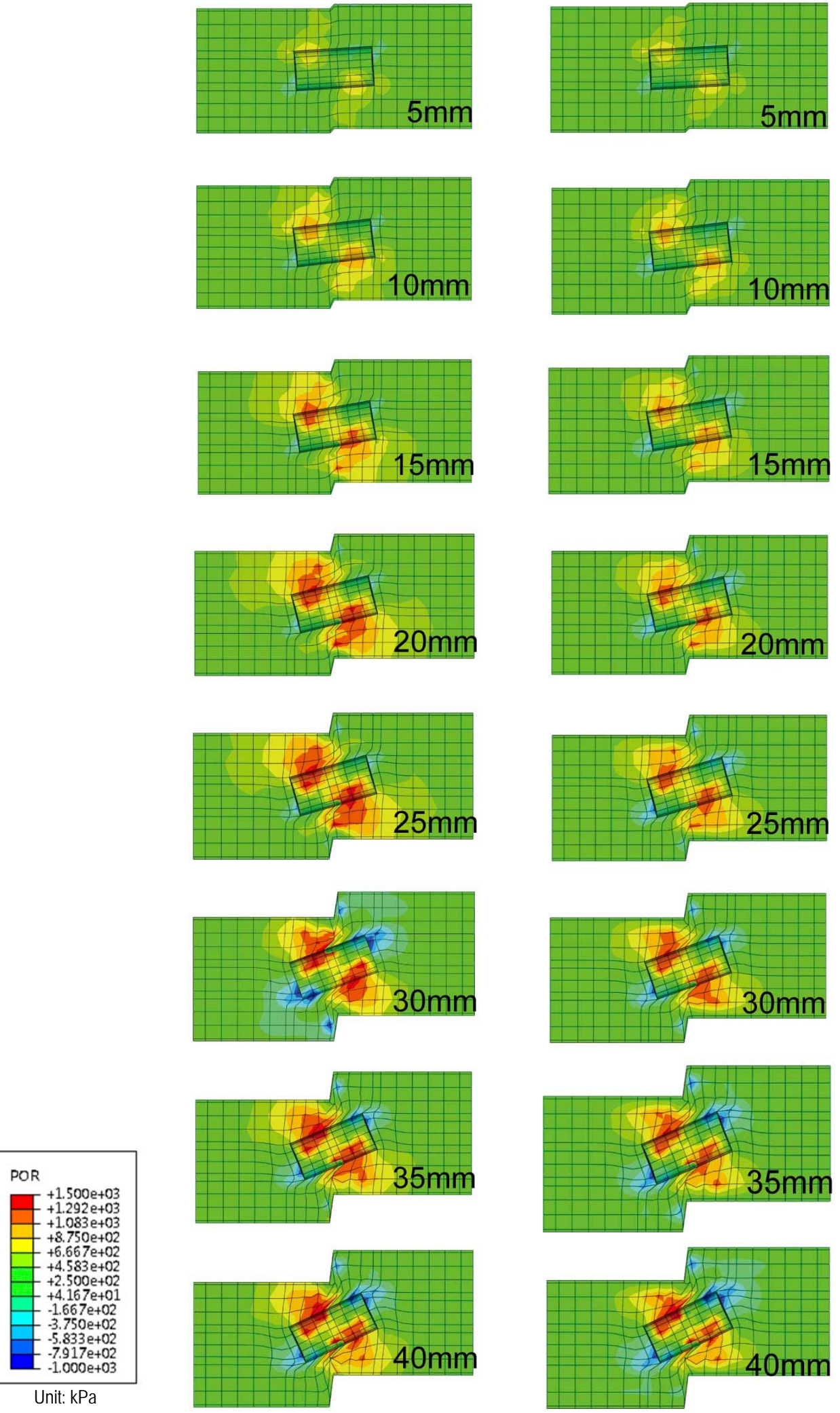

(a) Case 2 (Shear rate $0.1 \mathrm{~m} / \mathrm{s}$ )

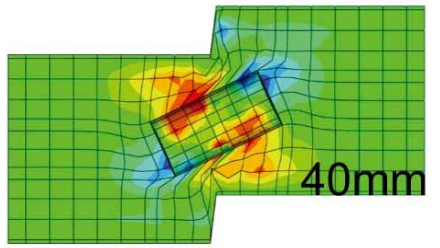

(b) Case 3 (Shear rate $0.01 \mathrm{~m} / \mathrm{s}$ )

Fig.12 Change of porewater pressure distribution on mesh with different displacement up to $40 \mathrm{~mm}$ for Case 2 and Case 3 


\section{References}

(1) JNC, H12 Project to establish the scientific and technical basis for HLW disposal in Japan, Project Overview Report, $2^{\text {nd }}$ progress report on research and development for the geological disposal of HLW in Japan, JNC TN1410 2000-001 (2000).

(2) NUMO, "Basic Strategy for Selection Procedures for Preliminary Investigation Areas for the Disposal of HLW“, November 8, 2001 (2001). (in Japanese)

(3) NUMO, "Information Package" for open solicitation of volunteers for areas to explore the feasibility of constructing a final repository for high-level radioactive waste, December 2002 (2002).

(4) Takemura, M., Scaling Law for Japanese Interplate Earthquakes in Special Relation to Surface Faults and Damage, J. Seismological Society of Japan, Second Series, 51, 2 (1998) pp.211-228. (in Japanese)

(5) Sato, R., Abe, K., Okada, Y., Shimazaki, K., and Suzuki, Y. (Eds), Handbook of earthquake fault parameters (1989) pp.82-92, Japan Kajima Institute Publishing. (in Japanese)

(6) Matsuda, T., Magnitude and recurrence interval of earthquakes from a fault, J. Seismological Society of Japan, Second Series, 28, 2 (1975) pp.269-284. (in Japanese)

(7) Hirai, T., Tanai, K., Kikuchi, H., Suzuki, H., Takaji, K., and Ohnuma, S., Assessment on Mechanical Effects on Engineered Barrier Systems due to Fault Movement, JNC TN8400 2003-009 (2003). (in Japanese)

(8) Nishimura, M., Hirai, T., Tanai, K., and Yui, M., A Study of Mechanical Effect of Simulated Fault Movement on Engineered Barrier System, Mat. Res. Soc. Symp. Proc. Vol. 932 (2006) Materials Research Society.

(9) Hibbitt, Karlsson \& Sorensen Inc., ABAQUS, 100 Medway St., Providence Rhode Island (1998).

(10) Börgesson, L., Model shear tests of canister with smectite clay envelopes in deposition holes, SKB TR 86-26 (1986), Stockholm, Sweden.

(11) Börgesson, L., Modelling of buffer material behaviour. Some examples of material models and performance calculations, SKB TR 88-29 (1988), Stockholm, Sweden.

(12) Börgesson, L., and Hernelind, J., Earthquake induced rock shear through a deposition hole, SKB TR 04-02 (2003), Stockholm, Sweden.

(13) Schofield, A., and Wroth, C.P., Critical State Soil Mechanics (1968) McGraw-Hill, New York.

(14) Parry, R.H.G. (Ed), Stress-Strain Behaviour of Soils (1972) G. T. Foulis and Co., Henley, England. 